\title{
Pazopanib: Evidence review and clinical practice in the management of advanced renal cell carcinoma
}

María José Méndez-Vidal ${ }^{1}$, Áurea Molina², Urbano Anido ${ }^{3}$, Isabel Chirivella ${ }^{4}$, Olatz Etxaniz ${ }^{5}$, Eva Fernández-Parra ${ }^{6}$, Marta Guix ${ }^{7}$, Carolina Hernández ${ }^{8}$, Julio Lambea ${ }^{9}$, Álvaro Montesa ${ }^{10}$, Álvaro Pinto ${ }^{11}$, Silverio Ros ${ }^{12}$ and Enrique Gallardo ${ }^{13^{*}}$

\begin{abstract}
Background: Pazopanib is indicated in the first-line treatment of metastatic renal cell cancer (mRCC). The aim of this study was to review the efficacy, safety, and pharmacokinetics of pazopanib and see how these aspects are linked to clinical practice.

Methods: A non-exhaustive systematic review was conducted according to the three topics. No publication restrictions were imposed and the selected languages were Spanish and English. After that, a summary of the main results and findings of the review was presented and discussed during three meetings (one for each topic) with 13 medical oncologists that usually treat mRCC. At these meetings, a questionnaire on the first-line use of pazopanib in clinical practice was also drawn up. After the meetings, the questionnaire was completed by 60 specialist medical oncologists in renal cancer.

Results: The efficacy and safety of pazopanib have been demonstrated in several clinical trials, and subsequently confirmed in studies in real-world clinical practice. In addition to its clinical benefit and good safety profile, quality of life results for pazopanib, which compare favorably to sunitinib, make it a good option in the first-line treatment of patients. Special populations have been included in studies conducted with pazopanib, and it is safe for use in elderly patients, poor functional status, kidney failure, and mild or moderate hepatic impairment, and in patients with concomitant cardiovascular disease. The results of the questionnaire have shown that pazopanib is perceived as an effective drug, in which quality of life (QoL) outcomes are valued above all.

Conclusions: This paper offers a comprehensive and critical summary of efficacy, tolerability, and pharmacokinetics of pazopanib in the treatment of mRCC. Pazopanib is an effective treatment with an acceptable safety profile. Its QoL and tolerability results offer certain advantages when compared with other therapeutic alternatives, and its use appears to be safe in different patient profiles.
\end{abstract}

Keywords: Antineoplastic agents, Carcinoma, renal cell, Kidney neoplasms, Protein kinase inhibitors, Quality of life, Pazopanib

\footnotetext{
* Correspondence: egallardo@tauli.cat

${ }^{13}$ Oncology Department, Parc Taulí Hospital Universitari. Institut

d'Investigació i Innovació Parc Taulí I3PT. Universitat Autònoma de Barcelona,

Sabadell, Barcelona, Spain

Full list of author information is available at the end of the article
}

(c) The Author(s). 2018 Open Access This article is distributed under the terms of the Creative Commons Attribution 4.0 International License (http://creativecommons.org/licenses/by/4.0/), which permits unrestricted use, distribution, and reproduction in any medium, provided you give appropriate credit to the original author(s) and the source, provide a link to the Creative Commons license, and indicate if changes were made. The Creative Commons Public Domain Dedication waiver (http://creativecommons.org/publicdomain/zero/1.0/) applies to the data made available in this article, unless otherwise stated. 


\section{Background}

Renal cancer accounts for $2 \%$ of all cancers diagnosed in adults, although the incidence is higher in developed countries. Every year, approximately 295,000 new cases are diagnosed, and around 134,000 deaths are recorded $[1,2]$. The most common kidney cancer in adults is renal cell carcinoma (RCC), which accounts for $90 \%$ of malignant kidney tumors; of these, an estimated $80-85 \%$ are clear cell tumors. Other less commonly diagnosed tumors include papillary and chromophobe RCC $[3,4]$. Despite curative surgery of the localized tumor, it is estimated that approximately $30 \%$ of patients will subsequently develop metastatic disease [5].

Clear cell RCC are highly vascularized tumors that accumulate lipid and glycogen [6-8]. The identification of dysregulated signaling pathways in vascular endothelial growth factor (VEGF) and the mammalian target of rapamycin (mTOR) in the progression of RCC has led to the development and approval of molecules targeting these pathways for therapeutic purposes [9]. Tyrosine kinase inhibitors (TKI) and mTOR inhibitors are now therapeutic options in first-, second- and third-line treatment in patients with metastatic RCC (mRCC) [6, 10-12].

Pazopanib is a multikinase inhibitor which targets the VEGF receptor (VEGFR), the platelet-derived growth factor receptor (PDGFR) and c-Kit protein, inhibiting angiogenesis [13-15]. It is indicated in adult patients with $\mathrm{mRCC}$, both as a first-line treatment and after previous treatment with cytokines [16].
Given the large volume of evidence that is generated year after year in the field of oncology, publications that review and collect the most relevant data help professionals involved in the management of patients to keep informed of the latest developments, so reviews of the literature in oncology, as in other therapeutic areas, are relevant and necessary. On the other hand, it is known that the real world practice is much more complex and variable than the research environment. In addition, clinicians may have different opinions about the relative value of the published data, which may cause several professionals to opt for very different attitudes to face the same problem. Therefore, it could be interesting to have documents containing the review of published data along with expert opinions. This type of combined documents can be useful to know if published evidence is transferred / reflected in routine clinical practice. Moreover, they can help to improve the knowledge and as a consequence of the clinical practice, since they give a global vision both "theoretical" (published data) and "practical" (expert opinion), on a specific topic. Several review papers on the evidence of pazopanib in the first-line treatment of mRCC have been published in the last 5 years [17-23]. However, no single document has included data on the efficacy, tolerability and pharmacokinetics of pazopanib, combined, moreover, with the opinion of an expert group. The aim of this work was to conduct a review of pazopanib and compare it with the clinical practice. This review document presents the

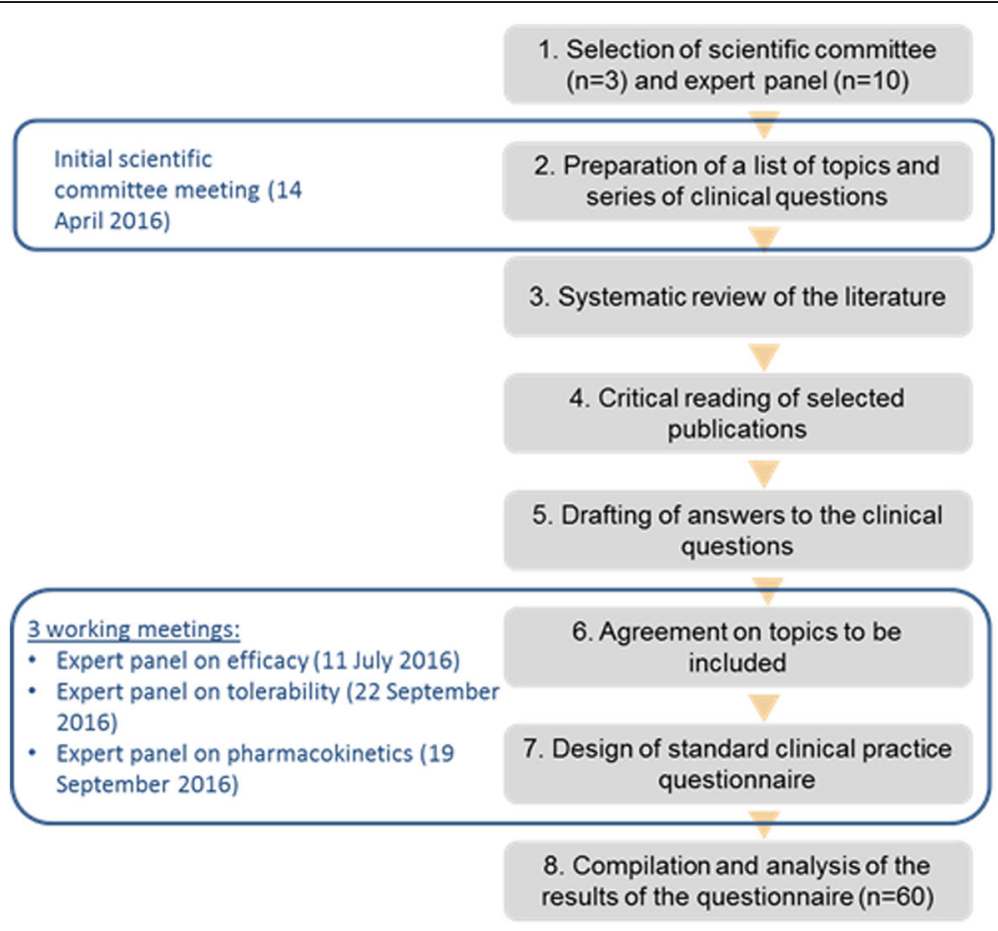

Fig. 1 Right 3 Study methodology 
available evidence published to date on the three fundamental aspects of pazopanib in the first-line treatment of mRCC: efficacy, tolerability and pharmacokinetics. It also includes a qualitative survey among specialist medical oncologists in renal cancer on certain aspects of standard clinical practice and the management of $\mathrm{mRCC}$ patients treated with pazopanib.

\section{Methods}

The methodology of this review article is summarized in Fig. 1. A scientific committee was formed, consisting of 3 specialist medical oncologists in kidney cancer, who, in an initial in-person meeting led by an expert moderator, agreed on a series of clinical questions. Clinical questions were categorized into 3 main sections: efficacy, safety, and pharmacokinetics of pazopanib. A non-exhaustive systematic review of the literature in Medline was then conducted to identify publications that could answer these questions. Generic key words employed were: "carcinoma, renal cell" $[\mathrm{MeSH}]$ AND "pazopanib"[All Fields] AND "humans"[MeSH Terms]. No publication date restrictions were imposed and articles in English or Spanish were included. For the pharmacokinetics section, a specific search was conducted which also included the following key words: "pharmacokinetics" OR "pharmacokinetic" OR "pharmacodynamics" OR "pharmacodynamic" OR "pharmacology". Each member of the scientific committee selected publications of interest for one of the sections. These articles were consulted and synthesized in specific templates. The resulting synthesis of articles was then used by a panel of another 10 specialist medical oncologists in renal cancer to draw up the responses to the proposed clinical questions. These responses were distributed and discussed, and a consensus was reached during 3 in-person meetings; all meetings were attended by a member of the scientific committee and several members of the expert panel. At the same meetings, a questionnaire on aspects of clinical practice related to the evidence on pazopanib in the treatment of mRCC was drawn up consensually (Table 1 ). The questionnaire was completed by 60 specialist medical oncologists in renal cancer, $68.3 \%$ of whom stated that they saw 10 or more mRCC patients a year, and $98.3 \%$ of whom had 3 or more years of experience in the area. The completion of the questionnaire was considered implied consent to participate. This document presents the evidence gathered, the conclusions of the expert panel, and the most relevant results obtained from the questionnaire.

\section{Results and discussion Pazopanib efficacy Progression-free survival}

Evidence on the effectiveness of pazopanib in the first-line treatment of $\mathrm{mRCC}$ has been obtained from several clinical trials which have shown a progression-free survival (PFS) of between 8 and 11 months, either compared to placebo or to sunitinib [14, 24]. The COMPARZ study demonstrated the non-inferiority of pazopanib compared to sunitinib in terms of PFS. This evidence is consistent with that obtained in a retrospective comparative study $[25,26]$ (Table 2) and also in the real-life retrospective SPAZO study $[25,26]$ which showed a PFS of 11.1 months. Other studies have reported PFS rates of between 10.5 and 14.1 months [19, 27-29].

\section{Response rate}

Response rate data are listed in Table 2. Response rates based on the independent evaluations performed in the VEG105192 and the COMPARZ studies were significantly superior to those obtained with placebo and sunitinib, respectively. On the other hand, the overall response rate with pazopanib in the SPAZO study [25, 26 ] was of $30.3 \%$, showing, as in the case of PFS, high consistency with published rates from clinical trials.

Recently, a post hoc exploratory analysis identified and described the clinical characteristics of patients in COMPARZ who exhibited a long-term response to pazopanib or sunitinib (patients with complete response (CR) / partial response (PR) or PFS $\geq 10$ and $\geq 18$ months), showing $\mathrm{PFS} \geq 10$ months in $31.4 \%$ patients and PFS $\geq 18$ months in $14.2 \%$ patients, and a shorter time to response with pazopanib compared with sunitinib (11.9 vs 17.4 weeks).

\section{Overall survival}

Mean overall survival (OS) in the VEG105192 study was not statistically significant (Table 2). This may be explained by the frequent and early switching of patients in the placebo arm to the pazopanib arm, and the inclusion of patients both previously treated and previously untreated with cytokines [14, 30, 31]. In the COMPARZ study, no significant differences in mean OS were observed between pazopanib and sunitinib (Table 2), either in the main study or the latest update: 28.3 vs. 29.1 months, respectively [32]. In various real-world clinical practice studies, a mean OS of 19-40.8 months has been described, probably depending on the proportion of patients with poor prognosis included in the sample [27$29,33]$. Recent studies with the new second-line treatments recommended by the ESMO guidelines, such as nivolumab and cabozantinib, show that after the administration of pazopanib in first line, the median OS for cabozantinib in second line is 22 months, while median OS for nivolumab has not been reached at the time of publication of this manuscript [34-36].

\section{Quality of life}

In the pre-planned analysis of quality of life (QoL) in the VEG105192 study, no significant differences were 
Table 1 Questionnaire on the first-line use of pazopanib in clinical practice

\begin{tabular}{ll}
\hline Question \\
\hline $1 a \quad \begin{array}{l}\text { Is achieving a complete response or a partial response with pazopanib in first-line treatment directly } \\
\text { correlated with better OS ? }\end{array}$ \\
1b Is achieving a complete or partial response with pazopanib in first-line treatment directly correlated \\
with better PFS ? \\
$\begin{array}{l}\text { Even if there is no impact on OS, is the longer PFS in first-line treatment with pazopanib sufficient for } \\
\text { it to be considered as a standard treatment option? }\end{array}$
\end{tabular}

3 Should OS be considered as a primary objective in first-line studies?

Response options

1 (strongly disagree)

4 (strongly agree)

1 (strongly disagree)

4 (strongly agree)

$4 \quad$ When selecting pazopanib as a first-line treatment, to which parameter do you give more importance in daily clinical practice?

1 (strongly disagree)

4 (strongly agree)

a) Yes

b) No

a) OS

b) PFS

c) ${ }^{\mathrm{C}} \mathrm{QoL}$

$5 \quad$ Does reducing the dose of pazopanib compromise its efficacy?

1 (strongly disagree)

4 (strongly agree)

6 When prescribing a treatment, do you inform the patient about the different first-line treatment options in order to take into account their opinion and preference? $7 \mathrm{Ta}$ Is pazopanib an appropriate first-line treatment for patients with clear cell carcinoma, ECOG $^{\mathrm{d}} 0$, and no
significant comorbidities?

7b Is pazopanib an appropriate first-line treatment for patients with brain metastases?

1 (strongly disagree)

4 (strongly agree)

1 (strongly disagree)

4 (strongly agree)

1 (strongly disagree)

4 (strongly agree)

7c Is pazopanib an appropriate first-line treatment for patients with concomitant cardiovascular disease?

1 (strongly disagree)

4 (strongly agree)

7d Is pazopanib an appropriate first-line treatment for patients with concomitant liver disease?

7e Is pazopanib an appropriate first-line treatment for patients with non-clear cell histologies?

1 (strongly disagree)

4 (strongly agree)

1 (strongly disagree)

4 (strongly agree)

$7 f$ Is pazopanib an appropriate first-line treatment for patients with moderate to severe renal failure $\left(\mathrm{CrCl}{ }^{\mathrm{e}} \leq 30\right)$ ?

$7 \mathrm{~g}$ Is pazopanib an appropriate first-line treatment for patients with ECOG $\geq 2$ ?

$7 e$

Is pazopanib an appropriate first-line treatment for patients with a poor prognosis?

$7 f \quad$ Is pazopanib an appropriate first-line treatment for patients with asymptomatic heart disease and fLVEF $<50 \%$ ?

8 When starting treatment with pazopanib in patients treated with oral anticoagulants, what do you do in your standard clinical practice?

With regard to patient age and pazopanib treatment, indicate your level of agreement with the following statement: "I do not prescribe pazopanib in patients older than 80 years of age"

$9 \mathrm{~b}$ With regard to patient age and pazopanib treatment, indicate your level of agreement with the following statement: "In patients over 70 years of age, I prescribe treatment at a dose of $800 \mathrm{mg} /$ day".

10

If biomarkers for pazopanib response were available, which would be most useful for you in your daily clinical practice?

11 With regard to tolerability, place in order of importance, from highest to lowest, the following factors to be taken into account when prescribing pazopanib.

Is it advisable to temporarily suspend treatment with pazopanib, and to continue with radiological monitoring, in order to reduce pazopanib toxicity (stop-and-go strategy)?

If pazopanib toxicity develops, what do you do in the case of grade 2 gastrointestinal toxicity?

If pazopanib toxicity develops, what do you do in the case of grade 3-4 gastrointestinal toxicity?
1 (strongly disagree)

4 (strongly agree)

1 (strongly disagree)

4 (strongly agree)

1 (strongly disagree)

4 (strongly agree)

1 (strongly disagree) 4 (strongly agree)

a) Change treatment to ${ }^{9} \mathrm{LMWH}$

b) Continue ${ }^{\mathrm{h}} \mathrm{OAC}$ treatment

1 (strongly disagree)

4 (strongly agree)

1 (strongly disagree) 4 (strongly agree)

a) Biomarkers predicting toxicity

b) Biomarkers predicting efficacy

a) Functional status

b) Concomitant diseases

c) Age

d) Social support

1 (strongly disagree)

4 (strongly agree)

a) Maintain the dose

b) Reduce the dose

c) Discontinue treatment

a) Maintain the dose

b) Reduce the dose

c) Discontinue treatment

a) Maintain the dose 
Table 1 Questionnaire on the first-line use of pazopanib in clinical practice (Continued)

\begin{tabular}{ll}
\hline Question & Response options \\
\hline times the normal value)? & $\begin{array}{l}\text { b) Reduce the dose } \\
\text { c) Discontinue treatment }\end{array}$ \\
$\begin{array}{lll}\text { If the patient shows complete response to pazopanib, what do you do in your standard clinical } & \text { a) Maintain the dose } \\
\text { practice? } & \text { b) Adjust the therapeutic regimen } \\
& \text { c) Discontinue treatment }\end{array}$
\end{tabular}

a OS: overall survival; ${ }^{b}$ PFS: progression-free survival; ${ }^{c} Q o L$ : quality of life; ${ }^{d} E C O G$ : Eastern Cooperative Oncology Group; ${ }^{e} C r C l$ : creatinine clearance; ${ }^{\mathrm{f}} \mathrm{LVEF}$ : left ventricular ejection fraction; ${ }^{9} \mathrm{LWMH}$ : low molecular weight heparin; ${ }^{\mathrm{h}} \mathrm{OAC}$ : oral anticoagulants

observed between the QoL with pazopanib or placebo, as assessed using the EORTC-QLQ-C30 and EQ-5D questionnaires and the EQ-5D visual analog scale [14]. The COMPARZ study also evaluated patient QoL, observing a significant improvement with pazopanib in 11 of the 14 domains that assessed health-related quality of life (HRQoL) during the first 6 months of treatment [24]. In the PISCES study (a patient preference study), HRQoL was evaluated using the Functional Assessment of Chronic Illness Therapy-Fatigue (FACIT-Fatigue) scale: pazopanib obtained a 2.5-point higher score than sunitinib (95\% CI: 0.92-4.07; $p<0.002$ ). The Supplementary Quality of Life Questionnaire (SQLQ) questionnaire also showed better results with pazopanib in 5 parameters [37, 38]. Finally, in a post-hoc analysis, a trend towards a lower risk of experiencing a $>20 \%$ loss of QoL was observed with pazopanib compared to placebo [39].

\section{Expert opinion in standard clinical practice}

Evidence published on the effectiveness of pazopanib is consistent and positions pazopanib as a standard treatment option. In view of the positive results for pazopanib in terms of OS and PFS, we asked the experts who completed the questionnaire about how these parameters relate with complete or partial response obtained with pazopanib, and how important these parameters are when considering pazopanib as an initial treatment option. In total, $85 \%$ of respondents agreed or strongly agreed that the complete or partial response rates achieved with pazopanib are directly correlated with a higher PFS, while $57.5 \%$ of respondents associated these parameters with a longer OS. In addition, 95\% of respondents agreed that the longer PFS in first line is sufficient to consider pazopanib as a standard treatment option.

Almost 50\% of the specialists who responded to the questionnaire stated that they give more importance to QoL as an efficacy parameter than to PFS or OS when selecting pazopanib as first-line treatment. In the case of complete response with pazopanib, $87.5 \%$ of respondents stated that they would maintain the therapeutic regimen, while $12.5 \%$ would discontinue it.

\section{Pazopanib tolerability}

Most adverse events recorded in the VEG105192 study with pazopanib were grade 1 or 2; $52 \%$ of patients had diarrhea; $40 \%$ arterial hypertension (AHT); 38\% hair depigmentation, $26 \%$ nausea; $22 \%$ anorexia; and $21 \%$ vomiting [14]. The incidence of grade 3 or 4 adverse events was $7 \%$ for placebo and 33\% for pazopanib, the most common being arterial hypertension and diarrhea.

The safety profiles of pazopanib and sunitinib in the COMPARZ study were significantly different [24] (Table 3). Patients who received pazopanib showed lower incidences of fatigue, hand-foot syndrome, stomatitis, leukopenia, thrombocytopenia, neutropenia, and anemia. No differences were observed in the incidence of cardiovascular adverse events, myocardial infarction or ischemia. In contrast, a higher incidence of elevated alanine aminotransferase (ALT) levels was reported with pazopanib. These differences in side effects between the two

Table 2 Pazopanib efficacy data from comparative studies

\begin{tabular}{|c|c|c|c|c|}
\hline VARIABLE & STUDY & DRUGS & OUTCOME & STATISTICS \\
\hline \multirow[t]{3}{*}{ Progression-free survival } & VEG105192 [14] & Pazopanib vs placebo & 11.1 vs 2.8 months & $\mathrm{HR}^{\mathrm{a}}=0.40 ; 95 \% \mathrm{Cl}^{\mathrm{b}}: 0.27-0.60$ \\
\hline & COMPARZ [24] (non-inferiority) & Pazopanib vs sunitinib & 8.4 vs 9.5 months & $\mathrm{HR}=1.05 ; 95 \% \mathrm{Cl}: 0.90-1.22$ \\
\hline & $\begin{array}{l}\text { International mRCC Database } \\
\text { Consortium (IMDC) [26] }\end{array}$ & Pazopanib vs sunitinib & 8.3 vs 8.3 months & $(\mathrm{HR}=1.08 ; 95 \% \mathrm{Cl}: 0.98-1.19)$ \\
\hline \multirow[t]{2}{*}{ Response rate } & VEG105192 & Pazopanib vs placebo & $30 \%$ vs $3 \%$ & $\begin{array}{l}\text { Pazopanib: } 95 \% \text { Cl: } 25.1-35.6 \\
\text { Placebo: } 95 \% \text { Cl: } 0.5-6.4\end{array}$ \\
\hline & COMPARZ (non-inferiority) & Pazopanib vs placebo & $31 \%$ vs $25 \%$ & $p=0.003$ \\
\hline \multirow[t]{2}{*}{ Overall survival } & VEG105192 [14] & Pazopanib vs placebo & 22.9 vs 20.5 months & $\mathrm{HR}=0.91 ; 95 \% \mathrm{Cl}: 0.71-1.16$ \\
\hline & COMPARZ (non-inferiority) & Pazopanib vs sunitinib & 28.4 vs 29.3 months & $\mathrm{HR}=0.91 ; 95 \% \mathrm{Cl}: 0.76-1.08$ \\
\hline
\end{tabular}


Table 3 Percentage of patients with adverse effects observed in the COMPARZ study

\begin{tabular}{|c|c|c|}
\hline ADVERSE EFFECT & PAZOPANIB & SUNITINIB \\
\hline \multicolumn{3}{|l|}{ Fatigue } \\
\hline Any grade & $50 \%$ & $63 \%$ \\
\hline Grade 3-4 & $10 \%$ & $17 \%$ \\
\hline \multicolumn{3}{|l|}{ Hand-foot syndrome } \\
\hline Any grade & $29 \%$ & $50 \%$ \\
\hline Grade 3-4 & $6 \%$ & $11 \%$ \\
\hline \multicolumn{3}{|l|}{ Stomatitis } \\
\hline Any grade & $14 \%$ & $27 \%$ \\
\hline$A L T^{b}$ & $60 \%$ & $43 \%$ \\
\hline Fatal $A E^{a} s$ & $2 \%$ & $3 \%$ \\
\hline Fatal treatment-related AEs & 3 cases & 8 cases \\
\hline
\end{tabular}

${ }^{\mathrm{a}} A E$ : adverse events; ${ }^{\mathrm{b}} A L T$ : alanine aminotransferase

drugs are maintained in patients who require dose adjustment during treatment: the incidence of hematologic adverse events and palmar-plantar erythrodysesthesia was higher in the sunitinib group compared to the pazopanib group, whereas scant differences were observed in diarrhea, fatigue, and hypertension [40].

Safety data from the pivotal studies were subsequently confirmed in real-world clinical practice. Table 4 gathers the main findings regarding to adverse events in three studies. In these studies adverse events were evaluated according to Common Terminology Criteria for Adverse Events (CTCAE). All grades adverse events were recorded in the study by Matrana et al and US cohort study. Only 3 and 4 grades are presented in SPAZO publication. Matrana et al. reported a study in patients treated with pazopanib after progression on first-line targeted treatment, in which $91 \%$ of the adverse events were grade 1 or 2 , and no treatment-related deaths occurred [28].

Table 4 Percentage of patients with adverse effects in real-world studies

\begin{tabular}{|c|c|c|c|}
\hline Adverse effect & Matrana $[28]^{*}$ & US cohort [33]* & SPAZO $[25]^{* *}$ \\
\hline Fatigue & $44 \%$ & $56 \%$ & $7.7 \%$ \\
\hline $\mathrm{AST}^{\mathrm{a}} / \mathrm{ALT}^{\mathrm{b}}$ & $35 \%$ & & $3.9 \% / 7.8 \%$ \\
\hline Diarrhea & $30 \%$ & $52 \%$ & $3.6 \%$ \\
\hline Hypothyroidism & $18 \%$ & & \\
\hline Nausea/vomiting & $17 \%$ & $40 \% / 44 \%$ & $-/ 1.1 \%$ \\
\hline Arterial hypertension & - & $27 \%$ & $4 \%$ \\
\hline Anemia & & & $2.6 \%$ \\
\hline Dropout rate & $12 \%$ & & $11.9 \%$ \\
\hline
\end{tabular}

${ }^{\mathrm{a}}$ AST aspartate aminotransferase; ${ }^{\mathrm{b}} A L T$ alanine aminotransferase

*All grades adverse events according to CTCAE; ${ }^{* *}$ Only grade $3-4$ adverse effects were reported
Neither deaths due to toxicity nor unexpected toxicities were reported in the Spanish SPAZO study. Although toxicity, especially low-grade toxicity, could have been underestimated as this was a retrospective study [25], the toxicity data for pazopanib in standard clinical practice are lower than those reported in clinical trials. This may due to the growing body of experience among specialists in the management of toxicities associated with renal cancer treatments, confirmed in the American cohort study, in which dose adjustment was reported in $17 \%$ of the patients [33], a lower percentage than reported in the COMPARZ study, along with a discontinuation rate of $24 \%$ and a mean daily dose of $664.9 \mathrm{mg}$ [24].

\section{Special populations}

To date, no data have been published on the use of pazopanib in patients with heart disease, although the potential cardiovascular adverse effects of pazopanib should be taken into account when prescribing pazopanib in patients with this profile. In clinical trials, $40-46 \%$ of patients had arterial hypertension [14, 24], although the incidence of cardiac dysfunction was less than 0.5$1 \%$ [16]. Blood pressure on starting treatment should be lower than 140/90 $\mathrm{mmHg}$ and if a patient develops severe hypertension or a hypertensive crisis, antihypertensive therapy should be administered, and the treatment should be suspended and restarted at a reduced dose, according to clinical criteria [16]. No evidence is available in patients treated with oral anticoagulants $(\mathrm{OAC})$, so if treatment is continued, the patient should be monitored closely.

No specific evidence is available on the use of pazopanib in patients with liver disease. Although cases of elevated ALT and AST have been reported, concomitant elevations of alkaline phosphatase or bilirubin are not generally observed [16]. In this population, it is recommended that liver function tests are performed before and during treatment with pazopanib. In case of mild or moderate liver failure (LF), the indications in the summary of product characteristics on administration and patient monitoring should be followed. In patients with moderate LF, the recommended dose is $200 \mathrm{mg}$ pazopanib once a day. However, pazopanib is not recommended in patients with severe LF.

The pivotal trials of pazopanib included patients with renal impairment (RI), but evidence in patients with creatinine clearance $(\mathrm{CrCl})<30 \mathrm{ml} / \mathrm{min}$ is limited. Good tolerability and a low incidence of serious adverse events were observed in a retrospective study of 9 patients with end-stage renal disease [41]. Some studies have included patients with mRCC on hemodialysis treated with TKI, in whom pazopanib was safe and effective and increased the life expectancy [42, 43]. Isolated proteinuria is not an indication for dose reduction, unless it is within the 
nephrotic range (> $3.5 \mathrm{~g} /$ day), or presents with edema, hyperlipidemia, or hypoalbuminemia [44].

\section{Expert opinion in standard clinical practice}

The results of the questionnaire survey show disparate opinions with regard to actions to be taken in the event of toxicity: $45 \%$ of the participants were of the view that temporarily suspending treatment with pazopanib could be an option to consider, while the other $55 \%$ disagreed. These differences may initially be explained by some vagueness regarding the type or grade of the toxicity in question; however, similar disparity was also observed in successive questions despite a more specific description of the situations. In the case of grade 2 gastrointestinal (GI) toxicity (4-6 bowel movements), half of the respondents stated that they would not reduce the dose, while the other half stated that they would, while for grade 3 or 4 GI toxicity, $57.5 \%$ stated that they would reduce the dose and the remaining $42.5 \%$ would discontinue treatment. Results also differed in the case of grade 1 or 2 liver toxicity. Lastly, in patients receiving OACs, most experts stated that they would switch treatment to low molecular weight heparins (LMWH), and only 15\% would reduce the OAC dose.

It was also noted in the questionnaire results that the patient's functional status and comorbidities are considered relevant when prescribing pazopanib. Ninety percent of experts considered these factors as quite or very important to take into account. While 65\% considered functional status as very important, the presence of comorbidities was considered very important by $30 \%$. Moreover, patient age and available social support were considered as of little or no importance by $90 \%$ of the respondents.

\section{Efficacy and safety of pazopanib in different patient profiles \\ Risk groups}

In the subgroup analysis of the COMPARZ study [24], the non-inferiority results for pazopanib compared to sunitinib in terms of PFS were independent of the risk groups, whether evaluated by the Memorial Sloan Kettering Cancer Center (MSKCC) classification [45] or the International Metastatic Renal Cell Carcinoma Database Consortium (IMDC) [46]. According to the MSKCC, mean PFS in low-risk patients with pazopanib was 13.7 months, 8.3 months in intermediate-risk patients, and 3.0 months in high-risk patients [47].

In the SPAZO study, the IMDC risk criteria were validated in first-line treatment with pazopanib, and efficacy and safety were demonstrated in all groups. In total, $19.4 \%$ of patients treated with pazopanib had a favorable prognosis, $57.2 \%$ intermediate, and $23.4 \%$ poor prognosis. Significant differences in PFS were observed in the 3 risk groups: 32.4 months in patients with a favorable prognosis, 11.1 months in the intermediate prognosis group, and 4 months in those with a poor prognosis [25]. In a recent observational study in which $12 \%$ of patients had an Eastern Cooperative Oncology Group (ECOG) score of 2 or higher, median PFS and OS were 12.5 and 26.5 months, respectively, in patients with intermediate/favorable risk; and 2.4 and 7.2 months in patients with a high risk, respectively [48].

Recently, an update of SPAZO 2 study results was presented in ESMO 2017. SPAZO 2 is an extension and update of SPAZO 1 trial with a total series of 530 patients in 50 centres treated in 1st line with pazopanib and a median follow up of 39.2 months. Population is somewhat different from SPAZO 1 trial with regard to the proportion of IMDC prognostic subgroups (14.2\% favorable, $61.9 \%$ intermediate and $24.9 \%$ poor prognosis). Results show a median PFS 9.8 months for the whole population, and 19.1, 10.4 and 5.2 months for favorable, intermediate and poor prognosis populations, respectively. Median OS were 19.6 months for the whole population, and 37.2, 20.8 and 7.2 for the favorable, intermediate, and poor prognosis populations, respectively. Relative risks were 32.9 for the whole population, and 58.9, 35.2 and $22.5 \%$ for the favorable, intermediate and poor prognosis populations, respectively. In this study, eligibility for clinical trials was tested as a prognostic factor. The study confirms the effectiveness of pazopanib in mRCC in the real world setting and concludes that ineligibility might be considered as a prognostic factor for PFS and OS (HR: 1.35; 95\% CI 1.05-1.73) [49].

Drug tolerability was not related with prognostic groups in any of the studies reviewed. However, the results of the observational studies which included patients with a worse prognosis or with ECOG 2 or higher [48] are similar to those obtained in the VEG105192 [14] and COMPARZ clinical trials [24].

\section{Age}

In registrational studies, $33 \%$ of the patients were older than 65 years of age, $3 \%$ were over 75 , and patients aged up to 83 years of age were recruited $[14,16]$. Elderly patients were also included in the COMPARZ and PISCES studies [24, 37]. Although no conclusions can be drawn due to the small number of elderly patients included in these trials, there do not appear to be any differences in effectiveness compared to sunitinib, and the safety profile among patients receiving pazopanib was similar, regardless of their age.

\section{Functional status and other factors}

In general, treatments show better PFS outcomes in patients with good prognosis, ECOG performance status of 0 , and a period of 1 year or more between the initial 
diagnosis and treatment for metastatic disease [50]. In the subgroup analysis of the COMPARZ study, PFS outcomes were similar for both treatments, regardless of the ethnicity, geographical origin or Karnofsky performance status of patients [24]. Although no specific analyses have been conducted, several observational studies have included patients with poor prognostic variables (ECOG $>2$, patients diagnosed less than 1 year previously, 3 or more MSKCC risk factors or 3 or 4 IMDC risk factors, histologies other than clear cell renal carcinoma, brain metastases, advanced age, or comorbidities), in which pazopanib has shown efficacy results consistent with those published in clinical trials $[25,29,51,52]$.

\section{Expert opinion in standard clinical practice}

Pazopanib has shown clinical benefit in all risk groups, regardless of age, tumor histology, location of metastases, and functional status or ECOG score. In this respect, the experts completing the questionnaire were asked how they perceived the appropriateness of using pazopanib in different patient profiles, depending on comorbidities, prognosis, site of metastases, or functional status. In total, $95 \%$ of respondents felt that pazopanib is a suitable option for the treatment of patients with clear cell histologies, no comorbidities, and ECOG 0 . Between 80 and $85 \%$ of respondents agreed that pazopanib was appropriate for use in the first-line treatment of patients with brain metastases, cardiovascular comorbidities, or ECOG of 2 or greater. Almost $80 \%$ saw pazopanib as a first-line treatment in patients with moderate-to-severe RI. Although, as outlined above, the available evidence is insufficient to advise against or contraindicate the use of pazopanib in the following cases, more than half of participants did not consider it as an appropriate first-line treatment in patients with concomitant liver disease, non-clear cell histology, or poor prognosis (Fig. 2). With regard to the appropriateness of using pazopanib in elderly patients, almost all respondents considered that patients over the age of 80 years are candidates for treatment with pazopanib, and almost $90 \%$ agreed that doses of $800 \mathrm{mg} /$ day could be prescribed in patients older than 70 years. This opinion was consistent with the populations of patients included in clinical trials and observational studies, which may reassure clinicians' performance in this specific group of patients.

\section{Efficacy and safety biomarkers and polymorphisms Biomarkers}

The discovery of biomarkers can be of use in predicting inter-patient differences in the efficacy and safety of antineoplastic agents and for identifying patients who are resistant to treatment. If the right drug is given to the right patient, the chances of response might increase, or the appearance of certain adverse reactions might be predicted, helping to achieve greater therapeutic success rates. Unfortunately, identifying these markers in the early stages of clinical development of the drugs remains a challenge, and they are generally identified when the medications have been administered to more extensive patient populations.

Arterial hypertension has been considered a biomarker of response to angiogenesis inhibitors [53]. In the case of pazopanib, a subanalysis of the COMPARZ study noted a trend (not statistically significant) towards a longer PFS in patients with a higher grade of systolic hypertension in weeks 4 and 12 of treatment ( $p=0.06$ and 0.07 , respectively), as well as a trend towards longer OS in patients with higher systolic hypertension in week $4(p=0.062)$ [54].

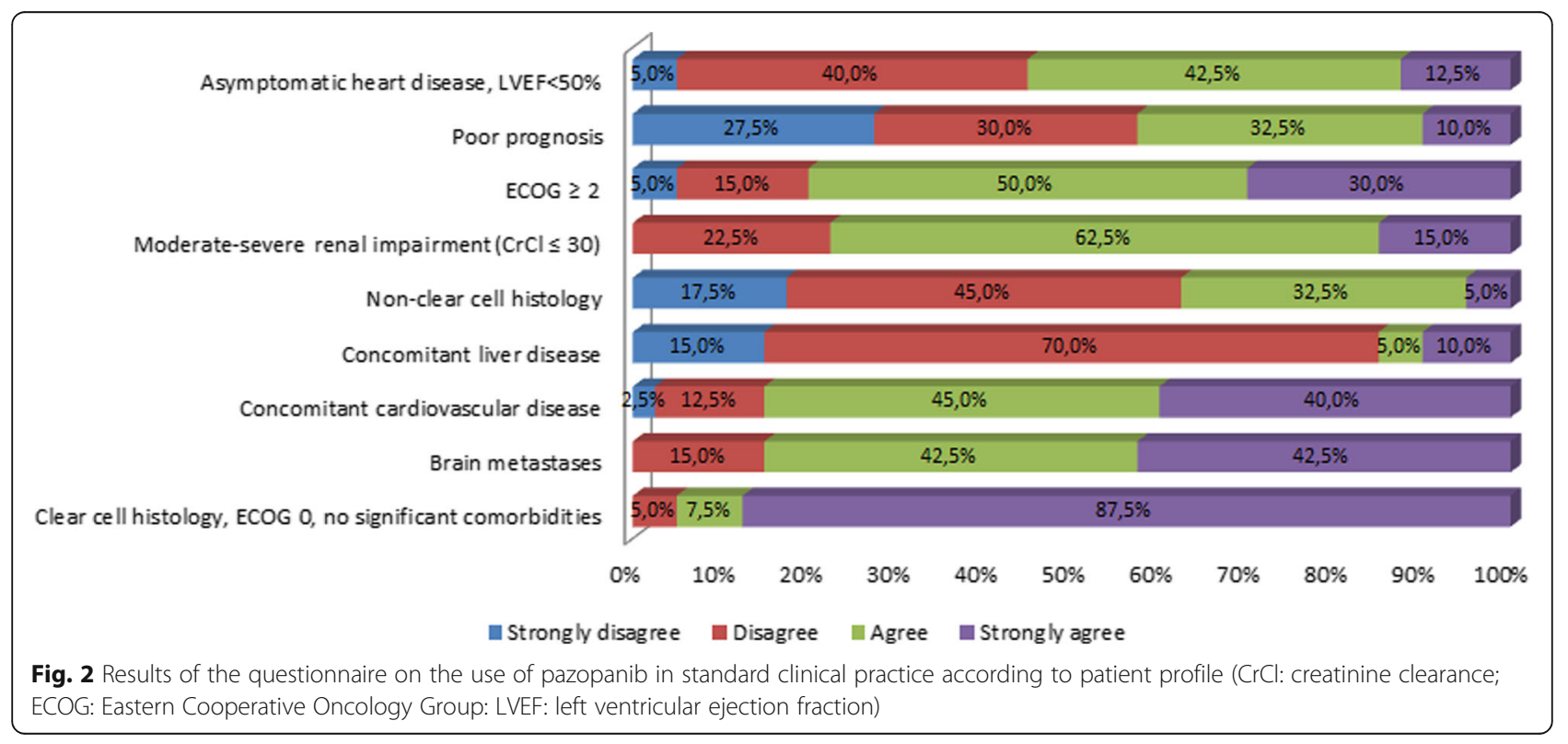


High baseline plasma concentrations of interleukin (IL)-6, IL-8, osteopontin and VEGF have been associated with an increased response to pazopanib in terms of OS, while high baseline levels of hepatocyte growth factor (HGF) have been associated with a lower OS in patients receiving pazopanib [55]. In another publication, high plasma concentrations of IL-8, osteopontin, HGF and tissue inhibitor of metalloproteinases 1 (TIMP1) were associated with a lower PFS in patients receiving pazopanib, while IL-6, IL-8 and osteopontin were also associated with a lower PFS in the placebo group. This latter finding might suggest a relationship between these 3 markers and RCC progression, rather than an association with response to pazopanib [56]. A recent subanalysis in patients in the COMPARZ study found that a mutation in the PBRM1 suppressor gene is associated with a better response to TKI, in the form of increased PFS and OS, as it seems to enhance the pro-angiogenic microenvironment of RCC. In contrast, the BAP1 mutation is associated with decreased angiogenic signaling and a poorer outcome for TKIs, manifesting as a shorter OS [57].

\section{Polymorphisms}

VEGF genotypes s833061TT, rs2010963CC, and rs699 947CC have been associated with a greater clinical benefit in patients receiving pazopanib [58]. Polymorphisms in the IL-8 gene and hypoxia-inducible factor $1 \mathrm{~A}$ (HIF-1A) have been associated with PFS in pazopanibtreated patients, and polymorphisms in the HIF-1A, nuclear receptor subfamily 1, group I, member 2 (NR1I2), and VEGFA genes have been associated with response rates [59]. The rs1126647 genotype of the IL- 8 gene has been associated with a shorter OS [60] and the variant rs34231037 in the VEGFR2 gene has been associated with greater sensitivity to pazopanib treatment [61].

The UGT1A1 TA-repeat polymorphism (Gilbert's syndrome) is significantly associated with increased bilirubin levels in patients treated with pazopanib [62]. TA7/TA7 homozygous or TA6/TA7 heterozygous patients can show an increased risk of developing hyperbilirubinemia when receiving pazopanib [63]. The VEGFR2 gene $+1416 \mathrm{~T}>\mathrm{A}$ (His472Gln) polymorphism has been associated with increases in blood pressure during treatment with pazopanib, particularly in AA homozygous patients. Similar results were observed with the VEGFA gene $-2578 \mathrm{C}>\mathrm{A}$, $-1498 \mathrm{C}>\mathrm{T}$ and $-634 \mathrm{G}>\mathrm{C}$ polymorphisms [64]. Specific polymorphisms such as the rs2858996/rs707889 in the HFE gene may be associated with reversible ALT elevation in patients treated with pazopanib [65].

\section{Expert opinion in standard clinical practice}

The identification of biomarkers that can predict response to antiangiogenic therapy may be of vital importance to $\mathrm{mRCC}$ patients. At present, no biomarkers that predict response to treatment with pazopanib have been validated prospectively, and as such, these data cannot be applied to clinical practice. In the questionnaire, $95 \%$ of respondents felt that if biomarkers were identified, those predicting efficacy would be more useful than those which predicted safety.

\section{Pazopanib pharmacokinetics}

According to the phase I study in patients with solid tumors treated with pazopanib, maximum plasma concentration $\left(\mathrm{C}_{\max }\right)$ and area under the curve $\left(\mathrm{AUC}_{0-24}\right)$ on day 1 increased as the pazopanib dose increased, up to the maximum dose of $2000 \mathrm{mg} /$ day. However, steady-state exposure is achieved at a dose of pazopanib $800 \mathrm{mg} /$ day [66].

Pazopanib is extensively bound to plasma proteins (99.9\%), regardless of its plasma concentration [67], and it is primarily excreted as unchanged drug in feces.

In the phase I study, a minimum plasma concentration $\left(\mathrm{C}_{\mathrm{min}}\right)$ of $15 \mathrm{mg} / \mathrm{l}$ or more was associated with a partial response [66]. A $C_{\min }$ of $\geq 20.5 \mathrm{mg}$ was subsequently associated with a greater reduction in tumor size $(37.9 \%$ vs. $6.9 \%$ with a $\mathrm{C}_{\min }<20.5 \mathrm{mg} / \mathrm{l}$ ) and a longer PFS (52 weeks vs. 19.6 weeks with a $C_{\min }<20.5 \mathrm{mg} / \mathrm{L}$ ) [68].

The greatest variability among patients treated with pazopanib is caused by the ingestion of fat in the diet, as this factor may double the AUC or $C_{\max }$ of the drug. Therefore, it is recommended that pazopanib is administered $1 \mathrm{~h}$ before or $2 \mathrm{~h}$ after meals. Other factors, such as age, race or gender, do not seem to be related to inter-patient variability $[69,70]$. The use of concomitant medications that alter gastric $\mathrm{pH}$ is also associated with inter-patient variability [68]. Genetic variability may also affect the response to pazopanib, although as noted above, no validated biomarkers are currently available. The concomitant administration of cytochrome P450 CYP3A4 inhibitors and pazopanib results in an increase in plasma concentrations, because pazopanib is a substrate of CYP3A4 and, to a lesser extent, CYP1A2 and CYP2C8 [71]. In contrast, CYP3A4 activity may be enhanced in patients with the NR1/2 $\mathrm{T}$ allele, resulting in increased pazopanib clearance [59].

The pazopanib dose of $800 \mathrm{mg}$ daily was selected on the basis of the phase II and III study data, plasma concentrations associated with the clinical and biological effects in preclinical models and in patients with solid tumors [72, 66], and because the steady-state plasma concentration of $20.5 \mu \mathrm{g} / \mathrm{ml}$ is associated with longer PFS and reductions in tumor size. Even so, pazopanib adverse events are dependent on plasma concentration [68], so the dose sometimes needs to be reduced, initially to $600 \mathrm{mg}$ and then to $400 \mathrm{or} 200 \mathrm{mg}$, if necessary [16]. In this context, it has been observed that the percentage 
of patients within the target window during fixed dosing is not significantly different from that of patients whose doses are adjusted [73]. On the other hand, a subanalysis of the COMPARZ study noted a longer PFS with both drugs in patients requiring a dose adjustment for the management of toxicities, suggesting that dose reductions or temporary treatment interruptions do not affect efficacy [40].

\section{Expert opinion in standard clinical practice}

If adverse effects appear, adjusting the pazopanib dose reduces toxicity and does not appear to compromise efficacy. In contrast to reports, the perception of most experts surveyed $(62.5 \%)$ is that reducing the pazopanib dose compromises efficacy.

\section{Conclusions}

This paper offers a comprehensive and critical summary of three important aspects of pazopanib in the treatment of mRCC: efficacy, tolerability, and pharmacokinetics. It also includes data on special populations and a summary of potential future biomarkers. The efficacy results of pazopanib in terms of PFS, OS and response rates are consistent across all studies.

Pazopanib is a treatment with an acceptable safety profile. Its QoL and tolerability results offer certain advantages when compared with other therapeutic alternatives, and its use appears to be safe in different patient profiles, including the elderly and patients with heart disease, mild or moderate liver failure, or poor functional status. Before pazopanib is indicated, the patient must be fully assessed, taking into account their functional status, comorbidities, and concomitant medications, rather than simply assessing patient age, thus minimizing toxicities. The first dose reduction in the event of adverse effects with pazopanib is from $800 \mathrm{mg}$ to $600 \mathrm{mg}$, and this adjustment does not appear to compromise efficacy. Intra- and inter-patient variability is mainly associated with gastric $\mathrm{pH}$ and food intake.

The questionnaire allowed us to compare the available evidence on the use of pazopanib with the perceptions of the drug among a group of medical oncologists, all experts in the treatment of RCC. The results of the questionnaire have shown that pazopanib is perceived as an effective drug, in which QoL outcomes are valued above all.

After reviewing the efficacy and safety data of the drug, this paper concludes that pazopanib can be used in patients of any prognostic group, functional status, and age. Observational studies also show that pazopanib is effective in patients with non-clear cell histology, brain metastases, and in different metastatic sites, although the opinion of the experts consulted may vary, as in the case of patients with liver diseases. In view of the above, we can conclude that the experts view pazopanib as a good first-line treatment option in the majority of patients with $\mathrm{mRCC}$.

\begin{abstract}
Abbreviations
AHT: Arterial hypertension; ALT: Alanine aminotransferase; AST: Aspartate aminotransferase; AUC0-24: Area under the curve; Cmax: Maximum plasma concentration; Cmin: Minimum plasma concentration; CR: Complete response; $\mathrm{CrCl}$ : Creatinine clearance; CTCAE: Common Terminology Criteria for Adverse Events; ECOG: Eastern Cooperative Oncology Group; FACITFatigue: Functional Assessment of Chronic Illness Therapy-Fatigue; GI: Gastrointestinal; HGF: Hepatocyte growth factor; HIF-1A: Hypoxiainducible factor 1A; LL: Interleukin; IMDC: International Metastatic Renal Cell Carcinoma Database Consortium; LF: Liver failure; LMWH: Low molecular weight heparins; mRCC: Metastatic renal cell cancer; MSKCC: Memorial Sloan Kettering Cancer Center; mTOR: Mammalian target of rapamycin; OAC: Oral anticoagulants; OS: Overall survival; PDGFR: Platelet-derived growth factor receptor; PFS: Progression-free survival; PR: Partial response; QoL: Quality of life; RCC: Renal cell carcinoma; RI: Renal impairment; SQLQ: Supplementary Quality of Life Questionnaire; TIMP1: Tissue inhibitor of metalloproteinases 1; TKI: Tyrosine kinase inhibitors; VEGF: Vascular endothelial growth factor; VEGFR: VEGF receptor
\end{abstract}

\section{Acknowledgements}

Financial support for the overall project was provided by Novartis. We thank to Novartis Oncology Spain and GOC Networking for their technical assistance throughout the process and for their medical editorial assistance with this manuscript.

\section{Funding}

This paper has received financial support from Novartis Oncology, who participated in the design of the study and the invitation of the participants of the questionnaire.

\section{Availability of data and materials}

The datasets used and/or analysed during the current study are available from the corresponding author on reasonable request.

\section{Authors' contributions}

All the authors have substantially participated in the following parts of the document: the conception and design of the study, or acquisition of data, or analysis and interpretation of data, drafting the article or revising it critically for important intellectual content, final approval of the version to be submitted.

\section{Ethics approval and consent to participate}

The questionnaire used in this article (opinion survey) did not need an ethics committee approval. This is regulated by the Spanish Medicines Agency, where this kind of surveys does not appear regulated, since they do not need approval (https://www.aemps.gob.es/investigacionClinica/medicamentos/ estudiosPostautorizacion.htm\#instrucciones)

\section{Consent for publication}

Not applicable.

\section{Competing interests}

Dr. EG states that he has participated in clinical trials sponsored by Novartis, Roche, Pfizer, and MSD; and advisory boards sponsored by Roche, Pfizer, BristolMyers Squibb, and Novartis. He has also received fees for presentations from Pfizer, Bristol-Myers Squibb, Bayer and Novartis, and travel expenses from Pfizer, Bristol-Myers Squibb, Bayer, and Novartis. Dr. AM and Dr. SR declare a conflict of interest with Novartis. MJMV has disclosed that she has served as a scientific advisor or consultant for Bristol-Myers Squibb, Novartis and Pfizer. The rest of the authors declare that they have no conflict of interest.

\section{Publisher's Note}

Springer Nature remains neutral with regard to jurisdictional claims in published maps and institutional affiliations. 


\section{Author details}

Oncology Department, Maimonides Institute of Biomedical Research (IMIBIC), Reina Sofia Hospital, Córdoba, Spain. ${ }^{2}$ Oncology Department, Complejo Hospitalario Universitario A Coruña, ACoruña, Spain. ${ }^{3}$ Oncology Department, Complejo Hospitalario Universitario de Santiago, Santiago de Compostela, Spain. ${ }^{4}$ Oncology Department, Hospital Clínico Universitario de Valencia, Valencia, Spain. ${ }^{5}$ Oncology Department, Hospital Universitari Germans Trias i Pujol, Badalona, Spain. ${ }^{6}$ Oncology Department, Hospital Nuestra Señora del Valme, Sevilla, Spain. ${ }^{7}$ Oncology Department, Hospital del Mar, Barcelona, Spain. ${ }^{8}$ Medical Oncology Department, Hospital Universitario Nuestra Señora de Candelaria, Santa Cruz de Tenerife, Spain. ${ }^{9}$ Medical Oncology Department, Hospital Clínico Universitario Lozano Blesa, Zaragoza, Spain. ${ }^{10}$ Medical Oncology Department, Hospital Regional de Málaga, Málaga, Spain. ${ }^{11}$ Medical Oncology Department, Hospital la Paz, Madrid, Spain. ${ }^{12}$ Oncology Department, Hospital Universitario Virgen de la Arrixaca, Murcia, Spain. ${ }^{13}$ Oncology Department, Parc Taulí Hospital Universitari. Institut d'Investigació i Innovació Parc Taulí I3PT. Universitat Autònoma de Barcelona, Sabadell, Barcelona, Spain.

Received: 27 July 2018 Accepted: 29 October 2018

Published online: 26 November 2018

\section{References}

1. Torre LA, Bray F, Siegel RL, Ferlay J, Lortet-Tieulent J, Jemal A. Global cancer statistics, 2012. CA Cancer J Clin. 2015;65:87-108.

2. Global Burden of Disease Cancer C, Fitzmaurice C, Dicker D, Pain A, Hamavid H, Moradi-Lakeh M et al. The Global Burden of Cancer 2013. JAMA oncology. 2015;1:505-527.

3. Moch H, Gasser T, Amin MB, Torhorst J, Sauter G, Mihatsch MJ. Prognostic utility of the recently recommended histologic classification and revised TNM staging system of renal cell carcinoma: a Swiss experience with 588 tumors. Cancer. 2000;89:604-14.

4. Leibovich $\mathrm{BC}$, Lohse $\mathrm{CM}$, Crispen $\mathrm{PL}$, Boorjian $\mathrm{SA}$, Thompson $\mathrm{RH}$, Blute $\mathrm{ML}$, et al. Histological subtype is an independent predictor of outcome for patients with renal cell carcinoma. J Urol. 2010;183:1309-15.

5. Janzen NK, Kim HL, Figlin RA, Belldegrun AS. Surveillance after radical or partial nephrectomy for localized renal cell carcinoma and management of recurrent disease. Urol Clin North Am. 2003;30:843-52.

6. Hsieh JJ, Purdue MP, Signoretti S, Swanton C, Albiges L, Schmidinger M, et al. Renal cell carcinoma. Nat Rev Dis Primers. 2017;3:17009.

7. Hakimi AA, Reznik E, Lee CH, Creighton CJ, Brannon AR, Luna A, et al. An integrated metabolic atlas of clear cell renal cell carcinoma. Cancer Cell. 2016;29:104-16.

8. Reuter VE, Tickoo SK. Differential diagnosis of renal tumours with clear cell histology. Pathology. 2010;42:374-83.

9. Finley DS, Pantuck AJ, Belldegrun AS. Tumor biology and prognostic factors in renal cell carcinoma. Oncologist. 2011;16(Suppl 2):4-13.

10. Rousseau B, Kempf E, Desamerica G, Boissier E, Chaubet-Houdu M, Joly $C$, et al. First-line antiangiogenics for metastatic renal cell carcinoma: a systematic review and network meta-analysis. Crit Rev Oncol Hematol. 2016;107:44-53.

11. Bedke J, Gauler T, Grunwald V, Hegele A, Herrmann E, Hinz S, et al. Systemic therapy in metastatic renal cell carcinoma. World J Urol. 2017;35:179-88.

12. Ljungberg B, Bensalah K, Bex A, Canfield S, Dabestani S, Hofmann F, et al. EAU guidelines on renal cell carcinoma: 2016 update. Available at: http:// uroweb.org/guideline/renal-cell-carcinoma/.

13. Hurwitz H, Dowlati A, Savage S, Fernando N, Lasalvia S, Whitehead B, et al. Safety, tolerability and pharmacokinetics of oral administration of GW786034 in pts with solid tumors. J Clin Oncol. 2005:23-3012.

14. Sternberg CN, Davis ID, Mardiak J, Szczylik C, Lee E, Wagstaff J, et al. Pazopanib in locally advanced or metastatic renal cell carcinoma: results of a randomized phase III trial. J Clin Oncol. 2010;28:1061-8.

15. Hutson TE, Davis ID, Machiels JH, de Souza PL, Baker K, Bordogna W, et al. Biomarker analysis and final efficacy and safety results of a phase $\|$ renal cell carcinoma trial with pazopanib (GW786034), a multi-kinase angiogenesis inhibitor. J Clin Oncol. 2008;26:5046.

16. Summary of product characteristics of Votrient ${ }^{\circledR}$. European Medicines Agency. Date of latest renewal: 08 January 2018. Available at: https://www. ema.europa.eu/documents/product-information/votrient-epar-productinformation_en.pdf.
17. Verheijen RB, Beijnen JH, Schellens JHM, Huitema ADR, Steeghs N. Clinical pharmacokinetics and pharmacodynamics of Pazopanib: towards optimized dosing. Clin Pharmacokinet. 2017;56:987-97.

18. Boudou-Rouquette P, Tlemsani C, Blanchet B, Huillard O, Jouinot A, Arrondeau J, et al. Clinical pharmacology, drug-drug interactions and safety of pazopanib: a review. Expert Opin Drug Metab Toxicol. 2016;12:1433-44.

19. Cella D, Beaumont JL. Pazopanib in the treatment of advanced renal cell carcinoma. Ther Adv Urol. 2016;8:61-9.

20. Welsh SJ, Fife K. Pazopanib for the treatment of renal cell carcinoma. Future oncology (London, England). 2015;11:1169-79.

21. McCormack PL. Pazopanib: a review of its use in the management of advanced renal cell carcinoma. Drugs. 2014;74:1111-25.

22. Kilonzo M, Hislop J, Elders A, Fraser C, Bissett D, McClinton S, et al. Pazopanib for the first-line treatment of patients with advanced and/or metastatic renal cell carcinoma : a NICE single technology appraisal. PharmacoEconomics. 2013;31:15-24.

23. Zivi A, Cerbone L, Recine F, Sternberg CN. Safety and tolerability of pazopanib in the treatment of renal cell carcinoma. Expert Opin Drug Saf. 2012;11:851-9.

24. Motzer RJ, Hutson TE, Cella D, Reeves J, Hawkins R, Guo J, et al. Pazopanib versus sunitinib in metastatic renal-cell carcinoma. N Engl J Med. 2013;369: 722-31.

25. Perez-Valderrama B, Arranz Arija JA, Rodriguez Sanchez A, Pinto Marin A Borrega Garcia P, Castellano Gaunas DE, et al. Validation of the international metastatic renal-cell carcinoma database consortium (IMDC) prognostic model for first-line pazopanib in metastatic renal carcinoma: the Spanish oncologic genitourinary group (SOGUG) SPAZO study. Ann oncol. 2016;27: 706-11.

26. Ruiz-Morales JM, Swierkowski M, Wells JC, Fraccon AP, Pasini F, Donskov F, et al. First-line sunitinib versus pazopanib in metastatic renal cell carcinoma: results from the international metastatic renal cell carcinoma database consortium. Eur J Cancer. 2016;65:102-8.

27. Santoni M, Conti A, Porta C, Procopio G, Sternberg CN, Basso U, et al. Sunitinib, pazopanib or sorafenib for the treatment of patients with late relapsing metastatic renal cell carcinoma. J Urol. 2015;193:41-7.

28. Matrana MR, Duran C, Shetty A, Xiao L, Atkinson BJ, Corn P, et al. Outcomes of patients with metastatic clear-cell renal cell carcinoma treated with pazopanib after disease progression with other targeted therapies. Eur J Cancer. 2013:49:3169-75.

29. Galvis V, Chow S, Thistlethwaite F. Clinical practice outcomes of patients treated with pazopanib for metastatic renal cell cancer (mRCC) - 6 year experience at a referral centre in Manchester, UK. Amsterdam: 38th Annual Conference of the European Society for Medical Oncology; September 27October 1, 2013; 2013.

30. Sternberg CN, Hawkins RE, Wagstaff J, Salman P, Mardiak J, Barrios CH, et al. A randomised, double-blind phase III study of pazopanib in patients with advanced and/or metastatic renal cell carcinoma: final overall survival results and safety update. Eur J Cancer. 2013;49:1287-96.

31. Sternberg CN, Davis ID, Deen KC, Sigal E, Hawkins RE. An open-label extension study to evaluate safety and efficacy of pazopanib in patients with advanced renal cell carcinoma. Oncology. 2014;87:342-50.

32. Motzer RJ, Hutson TE, McCann L, Deen K, Choueiri TK. Overall survival in renal-cell carcinoma with pazopanib versus sunitinib. N Engl J Med. 2014; 370:1769-70.

33. Vogelzang NJ, Hackshaw MD, Hutson TE, Bhowmik D, Yap M, Rembert D, et al. First-line and sequential use of Pazopanib followed by mammalian target of rapamycin inhibitor therapy among patients with advanced renal cell carcinoma in a US Community oncology setting. Clinical genitourinary cancer. 2015;13:210-7.

34. Choueiri TK, Escudier B, Powles T, Tannir NM, Mainwaring PN, Rini Bl, et al. Cabozantinib versus everolimus in advanced renal cell carcinoma (METEOR): final results from a randomised, open-label, phase 3 trial. The Lancet Oncology. 2016;17:917-27.

35. Motzer RJ, Escudier B, McDermott DF, George S, Hammers HJ, Srinivas S, et al. Nivolumab versus Everolimus in advanced renal-cell carcinoma. N Engl J Med. 2015;373:1803-13.

36. Escudier B, Porta C, Schmidinger M, Rioux-Leclercq N, Bex A, Khoo V, et al. Renal cell carcinoma: ESMO clinical practice guidelines for diagnosis, treatment and follow-up. Ann oncol. 2016;27:v58-68.

37. Escudier B, Porta C, Bono P, Powles T, Eisen T, Sternberg CN, et al. Randomized, controlled, double-blind, cross-over trial assessing treatment 
preference for pazopanib versus sunitinib in patients with metastatic renal cell carcinoma: PISCES study. J Clin Oncol. 2014;32:1412-8.

38. Mitchell CC, Parikh OA. Factors involved in treatment preference in patients with renal cancer: pazopanib versus sunitinib. Patient preference and adherence. 2014;8:503-11.

39. Cella D, Pickard AS, Duh MS, Guerin A, Mishagina N, Antras L, et al. Healthrelated quality of life in patients with advanced renal cell carcinoma receiving pazopanib or placebo in a randomised phase III trial. Eur J Cancer. 2012:48:311-23

40. Bjarnason GA, Kollmannsberger C, Ahmad QI, Dezzani L, Elmeliegy M, Han J, et al. annual meeting; June 2-6, 2017, editor. Effects of Pazopanib (PAZ) and Sunitinib (SUN) dose modification on safety and efficacy in metastatic renal cell carcinoma (mRCC) patients from COMPARZ. Chicago: Poster presented at the American Society of Clinical Oncology (ASCO).

41. Shetty AV, Matrana MR, Atkinson BJ, Flaherty AL, Jonasch E, Tannir NM. Outcomes of patients with metastatic renal cell carcinoma and end-stage renal disease receiving dialysis and targeted therapies: a single institution experience. Clinical genitourinary cancer. 2014;12:348-53.

42. Czarnecka AM, Kawecki M, Lian F, Korniluk J, Szczylik C. Feasibility, efficacy and safety of tyrosine kinase inhibitor treatment in hemodialyzed patients with renal cell cancer: 10 years of experience. Future oncology (London, England). 2015;11:2267-82.

43. Bersanelli M, Facchinetti F, Tiseo M, Maiorana M, Buti S. Pazopanib in renal cell carcinoma Dialysis patients: a mini-review and a case report. Curr Drug Targets. 2016;17:1755-60.

44. Alasker A, Meskawi M, Sun M, Ismail S, Hanna N, Hansen J, et al. A contemporary update on rates and management of toxicities of targeted therapies for metastatic renal cell carcinoma. Cancer Treat Rev. 2013;39:388-401.

45. Motzer RJ, Mazumdar M, Bacik J, Berg W, Amsterdam A, Ferrara J. Survival and prognostic stratification of 670 patients with advanced renal cell carcinoma. J Clin Oncol. 1999;17:2530-40.

46. Heng DY, Xie W, Regan MM, Warren MA, Golshayan AR, Sahi C, et al. Prognostic factors for overall survival in patients with metastatic renal cell carcinoma treated with vascular endothelial growth factor-targeted agents: results from a large, multicenter study. J Clin Oncol. 2009;27:5794-9.

47. Study VEG108844, A study of Pazopanib versus Sunitinib in the Treatment of Subjects with Locally Advanced and/or Metastatic Renal Cell Carcinoma. Available at: https://www.gsk-clinicalstudyregister.com/study/108844\#csr.

48. Kim MJ, Park SH, Lee JL, Lee SH, Lee SJ, Lim HY. A Korean multi-center, realworld, retrospective study of first-line pazopanib in unselected patients with metastatic renal clear-cell carcinoma. BMC Urol. 2016;16:46.

49. Arranz J, Pérez B, Rodríguez A, Chirivella I, Anido U, et al. SPAZO2 (SOGUG): Comparative effectiveness of pazopanib in metastatic renal carcinoma (mRC): Ineligible (I) vs eligible (E). patients for clinical trials. Ann Oncol. 2017; 28(Suppl 5):312

50. Hutson TE, Davis ID, Machiels JP, De Souza PL, Rottey S, Hong BF, et al. Efficacy and safety of pazopanib in patients with metastatic renal cell carcinoma. J Clin Oncol. 2010;28:475-80.

51. Buti S, Bersanelli M, Maines F, Facchini G, Gelsomino F, Zustovich F, et al, First-line PAzopanib in NOn-clear-cell renal cArcinoMA: the Italian retrospective multicenter PANORAMA study. Clinical genitourinary cancer. 2017;15:e609-e14.

52. Matrana MR, Baiomy A, Campbell M, Alamri S, Shetty A, Teegavarapu P, et al. Outcomes of patients with metastatic non-clear-cell renal cell carcinoma treated with Pazopanib. Clinical genitourinary cancer. 2017;15:e205-e8.

53. Murukesh N, Dive C, Jayson GC. Biomarkers of angiogenesis and their role in the development of VEGF inhibitors. Br J Cancer. 2010;102:8-18.

54. Goldstein D, Rosenberg JE, Figlin RA, Townsend RR, McCann L, Carpenter C, et al. Is change in blood pressure a biomarker of pazopanib and sunitinib efficacy in advanced/metastatic renal cell carcinoma? Eur J Cancer. 2016:53:96-104.

55. Liu Y, Tran HT, Lin Y, Martin AM, Zurita A, Sternberg CN, et al. 1404 POSTER DISCUSSION baseline (BL) IL-6, IL-8, and VEGF as predictive and prognostic markers for overall survival (OS) in metastatic renal cell carcinoma (mRCC) patients (pts) treated in a phase III trial of Pazopanib (PAZO) versus placebo (PL). Eur J Cancer. 2011;47:S170.

56. Tran HT, Liu Y, Zurita AJ, Lin Y, Baker-Neblett KL, Martin AM, et al. Prognostic or predictive plasma cytokines and angiogenic factors for patients treated with pazopanib for metastatic renal-cell cancer: a retrospective analysis of phase 2 and phase 3 trials. The Lancet Oncology. 2012;13:827-37.

57. Voss MH, Kuo F, Chen D, Cheng Y, Patel P, Redzematovic A et al. Integrated Biomarker Analysis for 412.Patients With Renal Cell Cancer Treated on the
Phase 3 COMPARZ Trial -. Correlating Common Mutation Events in PBRM1 and BAP1 With Angiogenesis Expression Signatures and Outcomes on Tyrosine Kinase Inhibitor Therapy. En: American Society of Clinical Oncology (ASCO) Annual Meeting; June 2-6, 2017; Chicago. Poster.4523

58. Bianconi M, Faloppi L, Loretelli C, Zizzi A, Giampieri R, Bittoni A, et al. Angiogenesis genotyping in the selection of first-line treatment with either sunitinib or pazopanib for advanced renal cell carcinoma. Oncotarget. 2016; 7:37599-607.

59. Xu CF, Bing NX, Ball HA, Rajagopalan D, Sternberg CN, Hutson TE, et al. Pazopanib efficacy in renal cell carcinoma: evidence for predictive genetic markers in angiogenesis-related and exposure-related genes. J Clin Oncol. 2011;29:2557-64.

60. Xu CF, Johnson T, Garcia-Donas J, Choueiri TK, Sternberg CN, Davis ID, et al. IL8 polymorphisms and overall survival in pazopanib- or sunitinib-treated patients with renal cell carcinoma. Br J Cancer. 2015:112:1190-8.

61. Maitland ML, Xu CF, Cheng YC, Kistner-Griffin E, Ryan KA, Karrison TG, et al. Identification of a variant in KDR associated with serum VEGFR2 and pharmacodynamics of Pazopanib. Clinical cancer research. 2015;21:365-72.

62. Xu CF, Reck BH, Xue Z, Huang L, Baker KL, Chen M, et al. Pazopanib-induced hyperbilirubinemia is associated with Gilbert's syndrome UGT1A1 polymorphism. Br J Cancer. 2010;102:1371-7.

63. Pick AM, Nystrom KK. Pazopanib for the treatment of metastatic renal cell carcinoma. Clin Ther. 2012;34:511-20.

64. Al-Marrawi MY, Rini B. Pazopanib for the treatment of renal cancer. Expert Opin Pharmacother. 2011;12:1171-89.

65. Xu CF, Reck BH, Goodman VL, Xue Z, Huang L, Barnes MR, et al. Association of the hemochromatosis gene with pazopanib-induced transaminase elevation in renal cell carcinoma. J Hepatol. 2011;54:1237-43.

66. Hurwitz HI, Dowlati A, Saini S, Savage S, Suttle AB, Gibson DM, et al. Phase I trial of pazopanib in patients with advanced cancer. Clinical cancer research. 2009;15:4220-7.

67. Imbs DC, Paludetto MN, Negrier S, Powell H, Lafont T, White-Koning M, et al. Determination of unbound fraction of pazopanib in vitro and in cancer patients reveals albumin as the main binding site. Investig New Drugs. 2016;34:41-8.

68. Suttle AB, Ball HA, Molimard M, Hutson TE, Carpenter C, Rajagopalan D, et al. Relationships between pazopanib exposure and clinical safety and efficacy in patients with advanced renal cell carcinoma. Br J Cancer. 2014; 111:1909-16.

69. Deng Y, Sychterz C, Suttle AB, Dar MM, Bershas D, Negash K, et al. Bioavailability, metabolism and disposition of oral pazopanib in patients with advanced cancer. Xenobiotica. 2013:43:443-53.

70. Heath El, Chiorean EG, Sweeney CJ, Hodge JP, Lager JJ, Forman K, et al. A phase I study of the pharmacokinetic and safety profiles of oral pazopanib with a high-fat or low-fat meal in patients with advanced solid tumors. Clin Pharmacol Ther. 2010;88:818-23.

71. Harris PA, Boloor A, Cheung M, Kumar R, Crosby RM, Davis-Ward RG, et al. Discovery of 5-[[4-[(2,3-dimethyl-2H-indazol-6-yl)methylamino]-2pyrimidinyl]amino]-2-methyl-b enzenesulfonamide (Pazopanib), a novel and potent vascular endothelial growth factor receptor inhibitor. J Med Chem. 2008;51:4632-40.

72. Kumar R, Knick VB, Rudolph SK, Johnson JH, Crosby RM, Crouthamel MC, et al. Pharmacokinetic-pharmacodynamic correlation from mouse to human with pazopanib, a multikinase angiogenesis inhibitor with potent antitumor and antiangiogenic activity. Mol Cancer Ther. 2007;6:2012-21.

73. de Wit $D$, van Erp NP, den Hartigh J, Wolterbeek R, den Hollander-van Deursen $\mathrm{M}$, Labots $\mathrm{M}$, et al. Therapeutic drug monitoring to individualize the dosing of pazopanib: a pharmacokinetic feasibility study. Ther Drug Monit. 2015:37:331-8. 